\title{
Mortality in Dhaka Zoo due to Microbial Agents
}

\author{
Syed Ali Ahasan ${ }^{1}$ and Ahmed Ziaur Rahaman ${ }^{2}$ \\ ${ }^{1}$ Scientific Officer, Dhaka Zoo, Mirpur 1, Dhaka 1216, Bangladesh, ${ }^{2}$ Department of Medicine \& Surgery, Dinajpur Government Veterinary College, \\ Basherhat, Dinajpur 5200, Bangladesh
}

[Received 07 April 2007; Accepted 08 December 2007]

\begin{abstract}
A total of 32 mortality cases of captive animals at the Dhaka Zoo due to various infections was detected and reconfirmed at two reference laboratories in Bangladesh during the period February 2000 to February 2006. Among the 22 different animal species studied, highest incidence was observed with gaur (15.6\%), followed by spotted deer $(12.5 \%)$, rhesus macaque $(9.4 \%)$, common pea fowl $(6.2 \%)$ and others $(56.3 \%)$. A total 35 isolates belonging to six different genera was recovered from the diseased animals. Among the pathogens, Mycobacterium spp. was the most prevalent (27.8\%), which was followed by Coccidioides immitis (19.4\%), Escherichia coli (19.4\%), Salmonella spp. (13.9\%), Staphylococcus spp. (13.9\%), and Aspergillus spp. (5.6\%). Mycobacterium spp. and C. immitis showed the widest range of host susceptibility. Establishment of a standard microbiological laboratory at the Dhaka Zoo is necessary for early diagnosis of threatening infections among valuable captive animals in order to improve animal health as well as to reduce the morbidity rate.
\end{abstract}

Keywords: Mortality, Animal pathogens, Confirmatory diagnosis, Tuberculosis, Coccidioidomycosis

Many microscopic organisms naturally and peacefully exist in enormous quantities within animal bodies ${ }^{1}$. But many others are pathogens, including bacteria, viruses, fungi, prions and parasites, cause diseases in animals. Pathogens are easily spread; an animal may consume food or drink something that has been contaminated with infected faecal material, for example. An animal may be exposed while walking across contaminated ground. Some diseases are transmitted by biting insects; others are spread by sexual contact. Loss of polymorphism is common to many endangered species, but whether low genetic diversity correlates with loss of fitness remains unproven ${ }^{2}$. Most terrestrial carnivores lack the diversity of other mammals, and this homogeneity has been suspected as the cause of poor health and reproductive failure in captivity ${ }^{3-4}$. Studies have shown infection to be the principal cause of death in captive animals, and management to affect rates of juvenile mortality in captivity ${ }^{5}$.

Establishing an independent diagnostic laboratory in Dhaka Zoo and practicing accordingly is a much talked issue since 1999 when a considerable number of Royal Bengal tiger and Indian lions died due to tripanosomiasis. Since then, samples of valuable dead, while apprehended causes of death/disease due to microorganisms, were regularly sent to two reference laboratories, viz., Central Disease Investigation Laboratory (CDIL), Department of Livestock Services, Dhaka, Bangladesh, and Department of Health Services, Institute of Public Health (IPH), Dhaka, Bangladesh. This study discloses some facts of microbial infections affecting recurrently and alarmingly to Dhaka Zoo animals. By virtue of this disclosure, facility for taking care of susceptible animals and preventive measures would accurately be taken as a course of action easily. Present study was conducted to unveil and detect the organisms responsible for that mortality in advocating by pin point for further care, prevention and treatment of animals. Moreover, this study might open the door of essence of establishing independent laboratory in the Dhaka Zoo right in near future.

During the six-year period from February 2000 to February 2006, post-mortem samples of 32 captive animals belonging to 22 species died at the Dhaka Zoo due to infectious diseases were analyzed for aetiological diagnosis of infections agents. Preliminary aetiological diagnosis was carried out at the Research and Zoo Education Section of the Dhaka Zoo. For confirmation, the postmortem specimens were sent to the reference laboratories.

The chronological list of the animals died and the causative agents isolated from the diseased animals are summarized in Table 1. Among the captive animals, mortality due to microbial infections was observed with 5 (15.6\%) gaur, 4 (12.5\%) spotted deer, 3 (9.4\%) rhesus macaque, 2 (6.2\%) common pea fowl, and one each of 18 other species. The frequently isolated pathogens, in order of decreasing frequency, were Mycobacterium spp. (10 cases, 27.8\%), Coccidioides immitis (7 cases, 19.4\%), Escherichia coli (7 cases, 19.4\%), Salmonella spp. (5 cases, 13.9\%), Staphylococcus spp. (5 cases, 13.9\%), and Aspergillus spp. (2 cases, 5.6\%). Among the 32 specimens studied more than one pathogen was recovered from 4 cases, where E. coli was isolated along with Salmonella spp. or Staphylococcus spp. It was also found that Mycobacterium and C. immitis were the most common causes of death of the captive animals at Dhaka Zoo showing a wide range of host susceptibility.

*Corresponding author:

Dr. Ahmed Ziaur Rahman, Assistant Professor, Department of Medicine \& Surgery, Dinajpur Government Veterinary College, Basherhat, Dinajpur 5200, Bangladesh Tel (Office): (0531) 61347; Cell: 01716 012105; E-mail: aziaurr@yahoo.com 
Table 1. List of captive animals died due to various infections at the Dhaka Zoo from February 2000 to February 2006

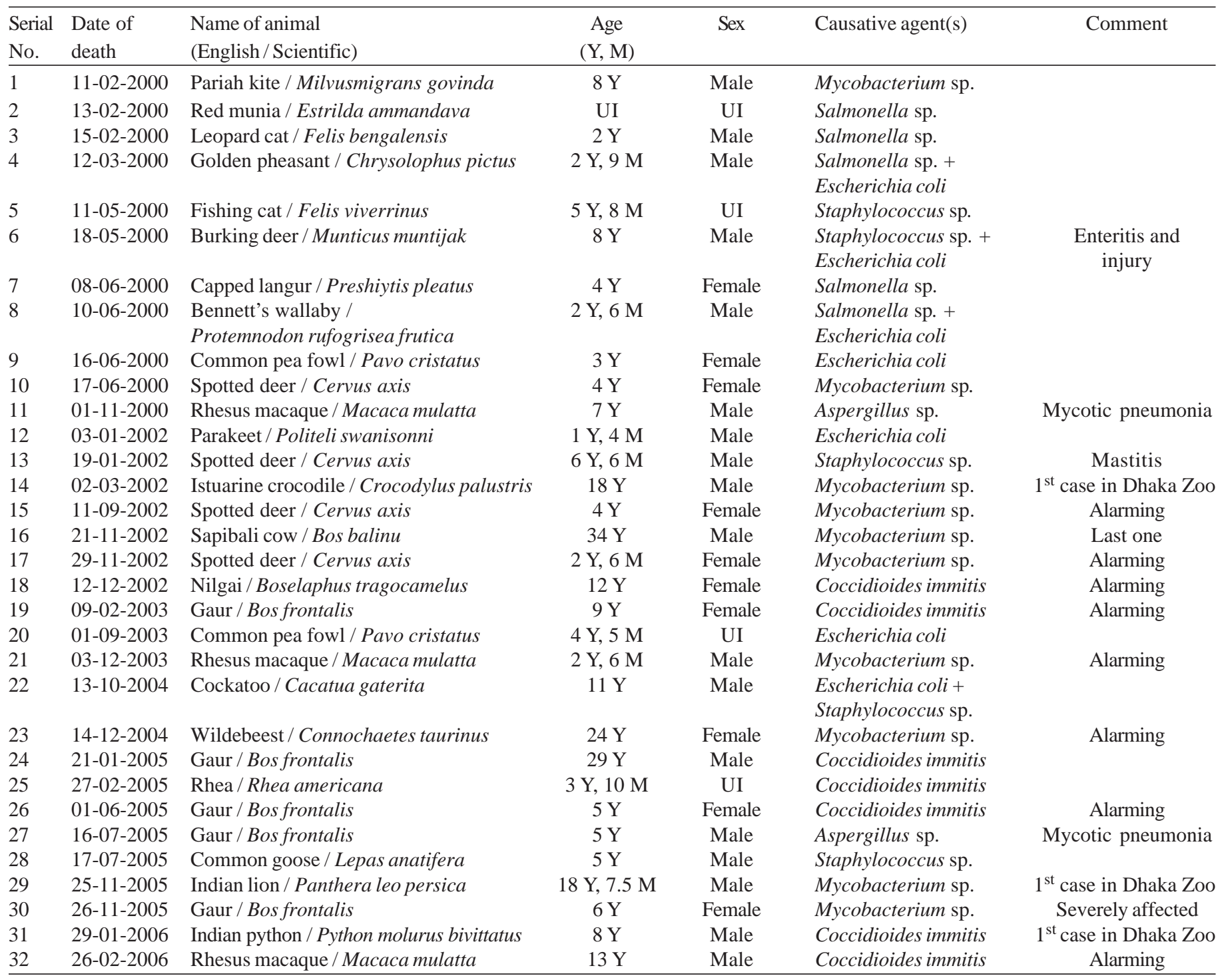

$\mathrm{Y}=$ Year(s); $\mathrm{M}=$ Month(s); UI = Unidentified.

Another study conducted by Research and Zoo Education Section of Dhaka Zoo during the period of February 2002 to September 2006 shows that the number of total death of different species was 144 of which tuberculosis alone comprised 35 cases (unpublished data). Other diseases included coccidioidomycosis, colibacillosis, salmonellosis, septicaemia and tetanus. It was further mentioned that 30 cases covered unidentified causes of death (only physical/ traumatic injurious death by any objects or by predators). At present, the prevention of infectious diseases in carnivores is a great challenge to the veterinarians and zoo staffs. Proper sanitation and immunoprophylaxis are hence important ${ }^{6}$.

Although the incidence of mycobacteriosis is currently low, outbreaks continue to occur in zoological collections ${ }^{7-10}$. Bovine tuberculosis is an important problem in framed deer from around the world and also has been noted sporadically from wild deer populations in several countries ${ }^{11}$. Several species of antelope have been reported with Mycobacterium bovis infections and a significant number of $M$. bovis infections have been reported in captive nonhuman primates at the Dhaka Zoo.
Mycobacteria may cause small epidemics among reptiles. In general, the infection occurs by ingestion. Post-mortem examination reveals the presence of tubercles, especially in the larger paranchymatous organs ${ }^{6}$. In one sloth bear at Nandankanan Zoo, Orissa, a case of natural infection of tuberculosis was reported ${ }^{12}$. Out of 214 captive wild herbivores of 18 species on histopathological examination, tuberculosis was recorded in 42 (19.6\%) animals belonging to 7 species in the study. The highest incidence (16.2\%) was noticed in the member of cervidae ${ }^{12}$.

One study on causes of mortality in captive bovid at Nandankanan Zoological Park, where data was collected for the period of 1968-1982 from the mortality records of 102 black bucks (Antelope cervicapra), 20 four-horned antelopes (Tetracerus quadricornis), 16 nilgais (Bosephalus tragocamelus), 8 gaurs (Bos gaurs) and 2 mithuns (Bos frontalis) ${ }^{13}$. Among infectious diseases, pulmonary tuberculosis was a major cause of death particularly in black bucks. In this surveillance, generalized tuberculosis in gaur and pulmonary tuberculosis in four-horned 
antelope were also recorded. This disease was considered as one of the most common maladies in all most all over Indian zoos $^{13}$.

Disease outcome depends on the immune status of the host young, geriatric and immuno- compromised individuals are highly susceptible to a severe disease outbreak of salmonellosis ${ }^{14}$. All persons involved in animal care and dealing, processing and preparing food and feed need to have proper education in sanitation and the potential risks of contamination of the collection or the food chain with Salmonella bacteria.

Disease prevention depends on good hygiene. Genetic resistance, maternal antibodies and optimal management and care practices all reduce disease prevalence. Control of environmental contamination, humidity and ventilation are thought important in prevention of colibacillosis in avian species ${ }^{15}$.

Escherichia coli serotypes in captive herbivorous animals are also isolated in Indian Zoo. At Assam State Zoo, Guwahati, a study was conducted on 24 dead animals of 11 different species based on the data during the period of 1988-1991 ${ }^{16}$. All the 24 specimens were examined and found positive for bacteria of the 28 strains of $E$. coli while 19 strains were typical and belonged to 16 different serotypes. Six strains were atypical and the remaining 3 strains were rough ${ }^{16}$.

Condition of the sheds, water house, space measurements and quality (soil topography, etc.) and feeding area were examined. It was observed that some sheds were to some extent eco-friendly and some were menagerie like captivity. There were no adequate laboratory facilities and a full fledged activity of veterinary unit. Shed cleaning systems were not scientific and feeding areas of maximum animals were not hygienic. Repeatedly foods were given day after day in the same place. It was also observed that water houses were not cleaned regularly due to some practical limitations.

Here in the Dhaka Zoo, the inbreeding effect is a serious problem by not having any breeding policy or road map. Inbreeding and loss of genetic variation decreases the ability of wild populations to adopt to extreme climatic changes, parasites, causing vulnerable to new diseases, parasitic pollutants, competitors and food supplies $^{17-18}$. So, further systematic study is highly needed and control measures are hence advisable according to the findings.

Record of water examination at the Dhaka Zoo by any higher laboratory like CDIL or IPH in any frequency was found nil. The water houses were brick made, which were not well cemented that usually encouraged algal growth and were not cleaned regularly. No tiles attachments were found in the water houses. This entire setback could predispose repeated contamination.

General people are sometime confused due to wrong information by both printing and electronic media. This creates a painful situation for the zoo managers and staffs. People do not know about the technicality or scientific reasons of various diseases affecting the animals ${ }^{19}$.

The present study demands routine aetiological diagnosis of various infections among the captive animals of the Dhaka Zoo.
Early diagnosis of curable infectious diseases would significantly reduce the mortality rate of the valuable animals in the zoo, for that a well equipped independent laboratory is required to be established in the Dhaka Zoo.

\section{References}

1. Breitschwerdt EB, Hegarty BC \& Hancock SI. 1998. Sequential evaluation of dogs naturally infected with Ehrlichia canis, Ehrlichia chaffeensis, Ehrlichia equi, Ehrlichia ewingii, or Bartonella vinsonii. J Clin Microbiol. 36: 2645-2651.

2. Munson L, Terio KA, Worley M, Jago M, Bagot-Smith A \& Marker L. 2005. Extrinsic factors significantly affect patterns of disease in free-ranging and captive cheetah (Acinonyx jubattus) population. $J$ Wildlife Dis. 41(3): 542-548.

3. O’Brien MER, Marker L, Newman A, Winkler CA, Meltzer D, Colly L \& Evermann JF. 1985. Genetic basis for species vulnerability in the cheetah. Science. 227: 1428-1434.

4. Marker-Kraus L. 1997. History of the cheetah (Acinonyx jubatus) in zoos 1829-1994. Int Zoo Yearbook. 35: 27-43.

5. Wielebnowski N. 1996. Reassessing the relationship between juvenile mortality and genetic monomorphism in captive cheetahs. Zoo Biol. 15: 353-369.

6. Fowler ME. 1986. Carnivores (Carnivore). In Zoo and Wild Animal Medicine (Fowler ME \& Miller RE eds ed), $2^{\text {nd }}$ edn, pp 160-161, 800807. WB Saunders Company, Philadelphia.

7. Bush M, Montali RJ, Phillips LG \& Holobaugh PA. 1999. Bovine tuberculosis in a bacterium camel herd: Clinical, therapeutic and pathologic findings. J Zoo Wild Med. 21: 171-179.

8. Flamand JRB. 1999. Medical aspects of Arabian oryx reintroduction. In Zoo and Wild Animal Medicine (Fowler ME \& Miller RE eds), $4^{\text {th }}$ edn, pp 687-698. WB Saunders Company, Philadelphia.

9. Mikota SK, Peddie L, Isaza R, et al. 2001. Epidemiology and diagnosis of mycobacterium tuberculosis in captive Asian elephants (Elephus maximus). J Zoo Wild Med. 32: 1-16.

10. Stetter MD, Mikota SK, Gutter AF, et al. 1995. Epizootic of Mycobacterium bovis in a zoological park. J Am Vet Med Assoc. 207: 1618-1621.

11. Cook RA, Fowler ME \& Miller RE. 1999. Mycobacterium bovis infection of cervids: Diagnosis, treatment, and control. In Zoo and Wild Animal Medicine: Current Therapy 4 (Fowler ME \& Miller RE eds), $4^{\text {th }}$ edn, pp 650-657. WB Saunders Company, Philadelphia.

12. Chakraborty A, Sharma DK \& Chaudhury B. 1993. Tuberculosis in captive wild herbivores. Indian J Vet Pathol. 17(2): 58-60.

13. Rao AT \& Acharjyo LN. 1996. Causes of mortality in captive bovid at Nandankanan Zoo. Indian Vet J. 73: 793-795.

14. Wray C \& Wray A. 2000. Salmonella in Domestic Animals. CAB Publishing Co, New York.

15. Dho-Moulin M \& Fairbrother JM. 1999. Avian pathogenic Escherichia coli (APEC). Vet Res. 30: 290-316.

16. Chakraborty A \& Sharma DK. 1992. In A Compendium of Publications from Indian Zoos (Patnaik SK \& Acharjyo LN eds), Vol 1, pp 372373. Indian Zoo Directors Association Publication, New Delhi.

17. Frankham R. 1995. Inbreeding and extinction: A threshold effect. Conserv Biol. 9: 792-799.

18. Heschel MS \& Paige KN. 1995. Inbreeding depression, environmental stress and population size variation in scarlet gilia, Ipomopsis aggregate. Conserv Biol. 9: 126-133.

19. Srivastav A \& Chakrabarty B. 2002. Seasonal distribution of deaths of tigers (Panthera tigris) in Indian Zoos. Zoo's Print J. 17(3): 741-743. 